Jurnal Ilmu Ilmu Agribisnis: Journal of Agribusiness Science, 9(3), Agustus 2021

\title{
ANALISIS KINERJA DAN STRATEGI PENGEMBANGAN USAHA PADA ROSE FLORIST DI BANDAR LAMPUNG
}

\author{
(Performance Analysis and Development Strategy of Agroindustry Rose Florist in Bandar Lampung) \\ Wenni Mey Kardepa Sembiring, Wuryaningsih Dwi Sayekti, Dame Trully Gultom
}

Jurusan Agribisnis, Fakultas Pertanian, Universitas Lampung, J1. Prof. Dr. Soemantri Brojonegoro No. 1

Bandar Lampung 35145. E-mail: wuryaningsih.dwisayekti@fp.unila.ac.id

\begin{abstract}
This study aims to analyze the existing performance of the Rose Florist agro-industry and formulate the business development strategy. This research uses a case study method with three respondents consisting of business owner, an employee of the business, and an UMKM officer. Data collection was carried out in April-May 2020. Data analysis uses cash flow and SWOT. The results showed that the Rose Florist Agroindustry has a good financial performance. There was an increase in cash of 9,538,729.17 from the cash flow statement, from the first period of IDR 153,249,128.57 to the second period of IDR 162,787,857.74. The development strategies that can be used in the development of the Rose Florist Agroindustry are to make quality flower arrangements, to add business signposts in business locations, and to train the workers on good management and better skills.
\end{abstract}

Keywords: agro-industry, performance, Rose Florist, strategy

\section{PENDAHULUAN}

Rose Florist didirikan pada tahun 2007 oleh Ibu Ernawati. Sedikit pengusaha yang tertarik dengan usaha bunga potong karena resiko yang tinggi dalam usaha tersebut, namun kini usaha bunga potong banyak diminati oleh pengusaha dan investor karena pendapatannya yang cukup tnggi. Salah satu usaha yang dapat dilakukan oleh Rose Florist dalam bersaing adalah dengan meningkatkan kinerja usahanya.

Kinerja usaha dalam suatu perusahaan menjadi salah satu tolok ukur keberhasilan perusahaan dalam mewujudkan tujuan untuk mendapatkan keuntungan. Kinerja usaha yang baik harus diwujudkan dengan memegang tanggung jawab atas pekerjaan. Oleh sebab itu, diperlukan perhatian khusus untuk mengetahui kinerja usaha dalam suatu perusahaan khususnya pada Rose Florist. Kinerja usaha yang baik dalam suatu perusahaan khususnya pada Rose Florist ditunjukkan dengan kondisi keuangan perusahaan yang dianalisis menggunakan analisis cash flow, sehingga diketahui keadaan keuangan yang mencerminkan prestasi kerja dalam periode tertentu (Fahmi 2011).

Strategi merupakan salah satu hal yang dibutuhkan dalam suatu usaha, agar usaha yang dijalankan bisa memberikan keuntungan yang lebih tinggi dari sebelumnya. Kenyataanya untuk mengembangkan usaha sangatlah sulit. Banyak hambatan-hambatan yang dihadapi, semua hambatan tersebut dapat diatasi dengan cara menyusun dan menerapkan strategi pengembangan usaha. Penelitian tentang "Analisis Kinerja dan Strategi Pengembangan Usaha pada Rose Florist di Bandar Lampung sangat diperlukan. Penelitian ini bertujuan untuk menganalisis kinerja usaha yang ada pada Rose Florist dan merumuskan strategi pengembangannya.

\section{METODE PENELITIAN}

Penelitian ini dilakukan di Rose Florist. Pengumpulan data dilaksanakan pada bulan AprilMei 2020. Penelitian menggunakan metode studi kasus. Responden berjumlah tiga orang, terdiri dari pemilik usaha, karyawan, dan dinas UMKM.

Jenis data yang digunakan dalam penelitian ini berupa data primer dan data sekunder. Data primer diperoleh melalui wawancara langsung kepada pemilik, karyawan, dan dinas UMKM (responden) dengan menggunakan daftar pertanyaan (kuesioner) terbuka, sedangkan data sekunder diperoleh dari instansi-instansi dan beberapa literatur yang relevan terkait dengan tema penelitian. Metode analisis yang digunakan dalam penelitian ini adalah analisis cash flow dan SWOT. 
Tabel 1. Format analisis arus kas

\begin{tabular}{lc}
\hline \multicolumn{2}{c}{ Nama Perusahaan Arus Kas Periode Tercakup } \\
\hline Kas yang dihasilkan (digunakan untuk) : & \\
Arus kas dari aktivitas operasi & $\mathrm{Rp} \mathrm{xx}$ \\
Arus kas dari aktivitas investasi & $\mathrm{Rp} \mathrm{xx}$ \\
Arus kas dari aktivitas pendanaan & $\underline{\mathrm{Rp} x x}$ \\
Kenaikan (penurunan) bersih dalam kas & $\mathrm{Rp} \mathrm{xx}$ \\
Kas pada awal periode & $\underline{\mathrm{Rp} \mathrm{xx}}$ \\
Kas pada akhir periode & $\mathrm{Rp} \mathrm{xx}$ \\
\hline
\end{tabular}

Analisis cash flow digunakan untuk mengetahui informasi mengenai sumber, penggunaan, perubahan kas, dan setara kas selama suatu periode akuntansi dan saldo kas pada tanggal pelaporan (Tanjung 2009). Cash flow digunakan untuk mengevaluasi kegiatan operasional yang telah berlangsung dan merencanakan investasi di masa depan. Cash flow juga digunakan untuk memberikan informasi mengenai kemampuan suatu perusahaan dalam menghasilkan kas dari aktivitas operasi, melakukan investasi, dan melakukan kewajiban. Analisis ini juga digunakan dalam penelitian Kaunang (2013) dan Wehantau dan Tinangon (2015). Format analisis Cash flow dapat dilihat pada Tabel 1.

Penyusunan strategi dalam penelitian ini melalui beberapa tahap. Tahap pertama, menentukan faktor-faktor lingkungan internal dan lingkungan eksternal yang mengacu pada Pratiwi, Hasyim dan Affandi (2016). Tahap ke dua, pemberian bobot dan rating yang kemudian dikalikan untuk mendapatkan skor total sehingga dapat ditentukan rangking pada masing-masing komponen menggunakan matriks IFE (Internal Factors Evaluation) dan EFE (External Factors Analysis Evaluation).

Tahap ke tiga, menyilangkan setiap komponen dari hasil perangkingan matriks IFE dan EFE untuk menghasilkan strategi pengembangan menggunakan matriks SWOT. Tahap ke empat, pemberian ranking terhadap strategi tersebut berdasarkan visi dan misi yang dimiliki agroindustri, sehingga diperoleh tiga belas strategi prioritas teratas berdasarkan analisis SWOT yang mengacu pada Rangkuti (2006).

Analisis SWOT juga digunakan dalam penelitian Putri , Sayekti, dan Rosanti (2014) tentang analisis pendapatan dan strategi pengembangan budidaya rumput laut di Pulau Pahawang Kecamatan Punduh Pidada Kabupaten Pesawaran dan penelitian Purba, Affandi, dan Nugraha (2016) tentang strategi pengembangan koperasi kredit (KOPDIT) Mekar Sai dalam pembiayaan agribisnis di Lampung.

Penentuan bobot mengacu pada teori David (2006), yaitu menentukan derajat kepentingan relatif menggunakan tabel catur. Penentuan bobot faktor internal dan eksternal dilakukan dengan memberikan bobot angka pada faktor kekuatan, kelemahan, peluang dan ancaman. Nilai pembobotan adalah sebagai berikut, nol jika faktor horizontal dianggap lebih penting daripada faktor vertikal, satu jika faktor vertikal dan horizontal dianggap sama-sama penting, dan dua jika faktor vertikal lebih penting daripada faktor horizontal.

\section{HASIL DAN PEMBAHASAN}

\section{Usaha Rose Florist}

Usaha Rose Florist merupakan salah satu usaha yang menjual berbagai macam jenis bunga, rangkaian bunga, dan papan bunga. Rose Florist terletak di Jalan Nusantara No. 11, Labuhan Ratu, Kedaton, Kota Bandar Lampung, Provinsi Lampung. Usaha ini dibangun karena kecintaan Ernawati terhadap bunga.

Arus kas pada Rose Florist dibagi menjadi dua periode yang bertujuan untuk membandingkan kedua periode agar dapat mengetahui Rose Florist berkembang dengan baik atau tidak. Laporan arus kas Rose Florist periode satu dan dua dapat dilihat pada Tabel 2 dan Tabel 3.

Tabel 2. Laporan cash flow pada Agroindustri Rose Florist periode I tahun 2019

\begin{tabular}{|c|c|}
\hline \multicolumn{2}{|c|}{$\begin{array}{c}\text { Rose Florist Bandar Lampung } \\
\text { laporan arus kas } \\
\text { Per 31 Desember 2019 } \\
\end{array}$} \\
\hline Arus kas dan aktivitas operasional & \\
\hline Penerimaan dari pelanggan & $293.485 .000,00$ \\
\hline Aset lancar lainnya & $7.052 .253,57$ \\
\hline Pembayaran ke pemasok & $-36.310 .750,00$ \\
\hline Pengeluaran operasional & $-107.783 .958,33$ \\
\hline $\begin{array}{l}\text { Kas bersih yang diperoleh dari aktivitas } \\
\text { oprasional }\end{array}$ & $156.442 .545,24$ \\
\hline Arus kas investasi & \\
\hline Peroleh/penjualan aset & $-1.500 .000,00$ \\
\hline Aktivitas investasi lain & \\
\hline Kas bersih diperoleh dari investasi & $-1.500 .000,00$ \\
\hline $\begin{array}{l}\text { Arus kas dari aktivitas keuangan } \\
\text { Pembayaran/penerimaan pinjaman } \\
\text { Kas dari aktivitas keuangan }\end{array}$ & $\begin{array}{l}- \\
-\end{array}$ \\
\hline $\begin{array}{l}\text { kenaikan secara tunai } \\
\text { saldo kas awal }\end{array}$ & $\begin{array}{r}154.942 .545,24 \\
-\end{array}$ \\
\hline saldo kas akhir & $154.942 .545,24$ \\
\hline
\end{tabular}


Tabel 3. Laporan cash flow pada Agroindustri Rose Florist periode II tahun 2019

\begin{tabular}{|c|c|}
\hline \multicolumn{2}{|c|}{$\begin{array}{c}\text { Rose Florist } \text { Bandar Lampung } \\
\text { laporan arus kas } \\
\text { Per 31 Desember 2019 }\end{array}$} \\
\hline Arus kas dan aktivitas operasional & \\
\hline Penerimaan dari pelanggan & $304.200 .000,00$ \\
\hline Aset lancar lainnya & $7.052 .253,57$ \\
\hline Pembayaran ke pemasok & $-35.154 .000,00$ \\
\hline Pengeluaran operasional & $-111.616 .979,17$ \\
\hline $\begin{array}{l}\text { Kas bersih yang diperoleh dari aktivitas } \\
\text { oprasional }\end{array}$ & $164.481 .274,40$ \\
\hline Arus kas investasi & \\
\hline Peroleh/penjualan aset & \\
\hline Aktivitas investasi lain & \\
\hline Kas bersih diperoleh dari investasi & \\
\hline Arus kas dari aktivitas keuangan & \\
\hline Pembayaran/penerimaan pinjaman & \\
\hline Kas dari aktivitas keuangan & \\
\hline kenaikan secara tunai & $164.481 .274,40$ \\
\hline $\begin{array}{l}\text { saldo kas awal } \\
\text { saldo kas akhir }\end{array}$ & $164.481 .274,40$ \\
\hline
\end{tabular}

\section{Analisis Cash Flow}

Tabel 2 dan Tabel 3 menunjukkan perbedaan dan persamaan laporan cash flow Rose Florist selama dua periode. Periode laporan arus kas Tabel 2 dihitung dari bulan Januari sampai dengan bulan Juni 2019. Periode laporan arus kas Tabel 3 dihitung dari bulan Juli sampai dengan bulan Desember 2019. Nilai arus kas dan aktivitas operasional pada Tabel 3 lebih tinggi yaitu sebesar Rp164.481.274,40 dibandingkan dengan nilai arus kas dan aktivitas operasional pada Tabel 2 sebesar Rp154.942.545,24.

Tabel 4. Matriks internal factor evaluation (IFE) untuk kekuatan

\begin{tabular}{lcccc}
\hline \multicolumn{1}{c}{ Faktor Internal } & Bobot & Rating & Skor & Ranking \\
\hline $\begin{array}{l}\text { Kekuatan } \\
\text { Rangkaian bunga } \\
\text { yang dihasilkan } \\
\text { berkualitas }\end{array}$ & 0,112 & 4 & 0,4516 & 1 \\
$\begin{array}{l}\text { Lokasi usaha } \\
\text { dekat dengan }\end{array}$ & & & & \\
$\begin{array}{l}\text { sasaran pasar } \\
\text { Sudah dilakukan } \\
\text { penerapan } \\
\text { manajemen } \\
\text { dengan baik }\end{array}$ & 0,1015 & 3 & 0,3044 & 3 \\
$\begin{array}{l}\text { Tenaga Kerja } \\
\text { dengan usia } \\
\text { matang memiliki }\end{array}$ & 0,1092 & 3 & 0,3277 & 2 \\
$\begin{array}{l}\text { keterampilan } \\
\text { lebih baik }\end{array}$ & 0,0987 & 3 & 0,2960 & 4 \\
$\begin{array}{l}\text { sudah melakukan } \\
\text { pemasaran secara } \\
\text { online di media } \\
\text { sosial }\end{array}$ & 0,0881 & 3 & 0,2643 & 5 \\
\hline \multicolumn{1}{c}{ Total } & & & & \\
\hline
\end{tabular}

Arus kas dan aktivitas operasional pada Tabel 3 lebih besar disebabkan oleh tingginya penerimaan pada periode kedua sebesar Rp304.200.000,00 yang berupa peningkatan permintaan produk Rose Florist, selain itu, pada laporan arus kas periode kedua tidak ada arus kas investasi seperti pada periode satu.

Hal ini menunjukkan bahwa Rose Florist memiliki kinerja keuangan yang baik dan akan berdampak bagi masa depan usaha Rose Florist, untuk dapat memperluas pasar dengan melakukan pembukaan cabang.

\section{Analisis Lingkungan Agroindustri Rose Florist}

Analisis lingkungan usaha merupakan proses awal dalam manajemen strategi yang bertujuan memantau lingkungan usaha Agroindustri Rose Florist. Penilaian terhadap lingkungan usaha berguna untuk mengidentifikasi kekuatan, kelemahan, peluang, dan hambatan pada saat ini dan pada masa mendatang yang dapat berpengaruh terhadap penyusunan strategi usaha.

\section{Analisis Lingkungan Internal}

Berdasarkan Tabel 4 dan Tabel 5 matriks internal factor evaluation (IFE), maka diperoleh kekuatan utama yang paling menentukan yaitu produk yang dihasilkan oleh Rose Florist berkualitas. Rose Florist merupakan agroindustri yang sedang berkembang sehingga senantiasa mempertahankan kualitas produk.

Tabel 5. Matriks internal factor evalution (IFE) untuk kelemahan

\begin{tabular}{llllr}
\hline \multicolumn{1}{c}{ Faktor Internal } & Bobot & Rating & Skor & Ranking \\
\hline $\begin{array}{l}\text { Kelemahan } \\
\text { Kurangnya kecepatan } \\
\text { rangkaian bunga }\end{array}$ & 0,0913 & 3 & 0,2739 & 4 \\
$\begin{array}{l}\text { Lokasi usaha yang } \\
\text { sulit dilalui }\end{array}$ & 0,1023 & 3 & 0,3069 & 2 \\
$\begin{array}{l}\text { Belum diterapkannya } \\
\text { secara rinci } \\
\text { pembukuan mengenai }\end{array}$ & & & & \\
$\begin{array}{l}\text { pengeluaran dan } \\
\text { penerimaan seluruh } \\
\text { produk di Rose Florist }\end{array}$ & 0,1024 & 3 & 0,3071 & 1 \\
$\begin{array}{l}\text { Tenaga kerja dengan } \\
\text { usia muda kurang } \\
\text { memiliki pengalaman } \\
\text { dan keterampilan }\end{array}$ & 0,0987 & 2 & 0,1974 & \\
$\begin{array}{l}\text { Belum lengkapnya } \\
\text { informasi mengenai } \\
\text { produk di media }\end{array}$ & & & & \\
sosial & & & & \\
\hline \multicolumn{1}{c}{ Total } & 1,0000 & & & \\
\hline
\end{tabular}


Tabel 6. Matriks eksternal factor evaluation (EFE) untuk peluang

\begin{tabular}{lcccc}
\hline \multicolumn{1}{c}{ Faktor Eksternal } & Bobot & Rating & Skor & Ranking \\
\hline $\begin{array}{l}\text { Peluang } \\
\text { Daya saing } \\
\text { produk tinggi }\end{array}$ & 0,1022 & 4 & 0,4090 & 1 \\
$\begin{array}{l}\text { Diminati oleh } \\
\text { berbagai lapisan } \\
\text { masyarakat }\end{array}$ & 0,0906 & 3 & 0,2717 & 4 \\
$\begin{array}{l}\text { Musim dingin } \\
\text { membuat bunga }\end{array}$ & & & & \\
$\begin{array}{l}\text { lebih tahan lama } \\
\text { Kecendrungan } \\
\text { orang }\end{array}$ & 0,0907 & 3 & 0,2720 & 3 \\
$\begin{array}{l}\text { mengungkapkan } \\
\text { perasaanya } \\
\text { melalui rangkaian }\end{array}$ & 0,0982 & 3 & 0,2945 & 2 \\
$\begin{array}{l}\text { bunga } \\
\text { Rose Florist lebih } \\
\text { mandiri tanpa } \\
\text { adanya peran } \\
\text { pemerintah }\end{array}$ & 0,1317 & 2 & 0,2634 & \\
\hline \multicolumn{1}{c}{ Total } & & & & \\
\hline
\end{tabular}

Kelemahan utama Rose Florist yaitu belum diterapkannya secara rinci pembukuan mengenai pengeluaran dan penerimaan seluruh produk yang ada di Rose Florist.

\section{Analisis Lingkungan Eksternal}

Berdasarkan Tabel 6 dan Tabel 7 maka diperoleh peluang utama yaitu daya saing produk tinggi, hal ini karena kebutuhan dan minat konsumen

Ancaman utama yaitu terdapat banyak pesaing dari usaha yang sejenis. Banyaknya pesaing dikarenakan banyaknya peminat dari produk tersebut sehingga banyak oraang-orang yang memulai untuk membuat usaha sejenis.

\section{Strategi Pengembangan}

Berdasarkan matriks evaluasi faktor internal dan eksternal dapat diketahui posisi untuk menentukan alternatif strategi Rose Florist. Posisi Rose Florist dapat di analisis menggunakan diagram analisis SWOT, sehingga menghasilkan titik kordinat $\mathrm{x}$ dan $\mathrm{y}$. Nilai $\mathrm{x}$ diperoleh dari selisih faktor internal (kekuatan - kelemahan) dan nilai y diperoleh dari selisih faktor eksternal (peluang ancaman) (Rangkuti, 2006). Posisi titik koordinat Rose Florist dapat dilihat pada Gambar 1.

Berdasarkan Gambar 1 maka diketahui bahwa Rose Florist berada pada kuadran I. Hasil penelitian ini sejalan dengan penelitian yang dilakukan oleh Putri, Lestari, dan Sayekti (2017) tentang kinerja dan strategi pengembangan PRIMKOPTI Kabupaten Pesawaran Provinsi -

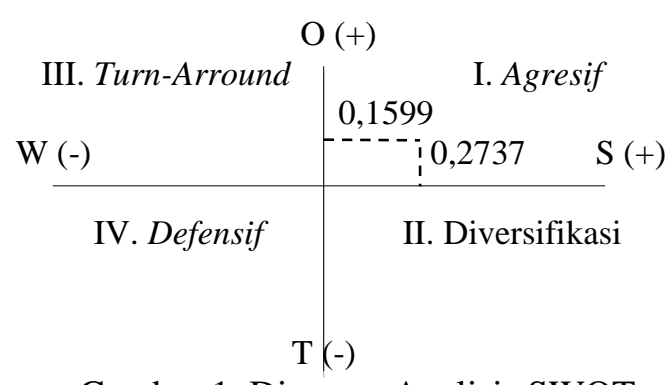

Gambar 1. Diagram Analisis SWOT

Lampung. Posisi Rose Florist dan PRIMKOPTI dalam diagram analisis SWOT berada pada kuadran 1 (strategi agresif) yang menggambarkan situasi sangat menguntungkan karena memiliki kekuatan dan peluang untuk keberlanjutan usaha. Strategi yang tepat pada kondisi ini adalah dengan cara memanfaatkan kekuatan untuk mengoptimalkan peluang yang ada (strategi S-O).

Strategi (S-O) dapat dicapai oleh Rose Florist dengan cara meningkatkan kualitas produk agar unggul dalam persaingan, Rose Florist lebih mandiri tanpa adanya peran pemerintah karena tenaga kerja telah memiliki menejemen yang baik dan keterampilan yang lebih baik, meningkatkan kegiatan pemasaran dan mengoptimalkan publikasi produk agar meningkatkan ketertarikan konsumen. terhadap produk Rose Florist tinggi.

Tabel 7. Matriks eksternal factor evaluation (EFE) untuk ancaman

\begin{tabular}{|c|c|c|c|c|}
\hline Faktor Eksternal & Bobot & Rating & Skor & Ranking \\
\hline Ancaman & & & & \\
\hline $\begin{array}{l}\text { Terdapat banyak } \\
\text { pesaing dari usaha } \\
\text { yang sejenis }\end{array}$ & 0,1057 & 3 & 0,3172 & 1 \\
\hline Permintaan yang & & & & \\
\hline $\begin{array}{l}\text { kurang sesuai } \\
\text { dengan kualitas } \\
\text { yang diberikan }\end{array}$ & & & & \\
\hline Rose Florist & 0,0981 & 3 & 0,2942 & 2 \\
\hline $\begin{array}{l}\text { Musim panas } \\
\text { membuat bunga }\end{array}$ & & & & \\
\hline cepat layu & 0,0830 & 3 & 0,2490 & 4 \\
\hline budaya & & & & \\
\hline $\begin{array}{l}\text { memberikan } \\
\text { bucket bunga }\end{array}$ & & & & \\
\hline sebgai ucapan & & & & \\
\hline akan tergantikan & & & & \\
\hline dengan budaya & & & & \\
\hline lain seperti & & & & \\
\hline $\begin{array}{l}\text { pemberian bucket } \\
\text { uang dan bucket }\end{array}$ & & & & \\
\hline sayur & 0,1094 & 2 & 0,2188 & 5 \\
\hline $\begin{array}{l}\text { Kurangnya peran } \\
\text { aktif dari }\end{array}$ & & & & \\
\hline $\begin{array}{l}\text { pemerintah } \\
\text { setempat terhadap }\end{array}$ & & & & \\
\hline Rose Florist & 0,0905 & 3 & 0,2715 & 3 \\
\hline Total & 1,0000 & & 1,3506 & \\
\hline
\end{tabular}


Strategi pengembangan didapatkan dari hasil persilangan faktor internal dan faktor eksternal, kemudian dari hasil persilangan dilakukan pendekatan visi dan misi Rose Florist. Penentuan dilakukan bersama pemilik Rose Florist dan terdapat 13 strategi yang bisa dterapkan, namun strategi prioritas utama yang dapat diterapkan ialah:

1) Memaksimalkan kualitas rangkaian bunga agar tetap bersaing dan tetap diminati oleh konsumen.

2) Menambahkan papan nama usaha di lokasi usaha yang berada di area pendidikan menjadi salah satu cara agar Rose Florist diminati oleh pelanggan karena mudah ditemukan.

3) Melakukan pelatihan pada tenaga kerja (SDM) agar Rose Florist lebih memiliki keterampilan yang baik dalam merangkai bunga.

\section{KESIMPULAN}

Berdasarkan penelitian yang dilakukan dapat disimpulkan bahwa Usaha Rose Florist memiliki usaha yang menguntungkan. Laporan arus kas menunjukkan bahwa kas periode kedua lebih besar dibandingkan periode pertama. Strategi pengembangan Rose Florist adalah membuat rangkaian bunga yang berkualitas, menambahkan papan nama usaha, dan melakukan pelatihan pada tenaga kerja.

\section{DAFTAR PUSTAKA}

David FR. 2006. Konsep Manajemen Strategi. PT Prehalindo. Jakarta.

Fahmi I. 2011. Analisis Laporan Keuangan. Alfabeta. Bandung

Kaunang JM. 2013. Analisis laporan arus kas sebagai alat ukur menilai kinerja pada PT. Pegadaian cabang Manado Timur. Jurnal Riset Ekonomi, Manajemen, Bisnis, dan Akuntansi:1(3):455-464. https://ejournal.unsr at.ac.id/index.php/emba/article/view/1845/145 6. [03 Februari 2021]

Pratiwi D, Hasyim AI, dan Affandi MI. 2016. Analisis finansial dan strategi pengembangan nanas madu di Kabupaten Lampung Timur. Jurnal Ilmu Ilmu Agribisnis:4(1):11-12. http://jurnal.fp.unila.ac.id/ind ex.php/JIA/article/view/1209/1106. [15 Juli 2020]

Purba MN, Affandi MI, dan Nugraha A. 2016. Strategi pengembangan koperasi kredit (KOPDIT) Mekar Sai dalam pembiayaan agribisnis di Lampung. Jurnal Ilmu Ilmu Agribisnis:4(3):285-293. http://jurnal.fp .unila.ac.id/index.php/JIA/article/view/1503/1 357. [03 Februari 2021]

Putri D, Sayekti WD, dan Rosanti N. 2014. Analisis pendapatan dan strategi pengembangan budidaya rumput laut di Pulau Pahawang Kecamatan Punduh Pidada Kabupaten Pesawaran. Jurnal Ilmu Ilmu Agribisnis:2(1):56-63.

http://jurnal.fp.unila.ac.id/index.php/JIA/articl e/view/561. [25 Juli 2020]

Putri RM, Lestari DAH, dan Sayekti WD. 2017. Kinrja dan Strategi Pengembangan PRIMKOPTI Kabupaten Pesawaran Provinsi Lampung. Jurnal Ilmu Ilmu Agribisnis:5(2):184-191. http://jurnal.fp .unila.ac.id/index.php/JIA/article/view/1657.

[03 Februari 2021]

Rangkuti F. 2006. Analisis SWOT : Teknik Membedah Kasus Bisnis. Gramedia Pustaka Utama. Jakarta.

Tanjung A. 2009. Akuntansi Pemerintah Daerah. Alfabeta. Bandung.

Wehantouw AB dan Tinangon. JJ. 2015. Analisis laporan arus kas operasi, investasi, dan pendanaan pada PT. Gudang Garam TBK. Jurnal Riset Ekonomi, Manajemen, Bisnis, dan Akuntansi:3(1):806-817. https://ejournal.unsrat.ac.id/index.php/e mba/article/view/7555. [03 Februari 2021] 